\title{
Desert networks: A conceptual model for the impact of scarce, variable and patchy resources
}

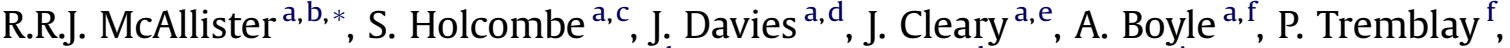 \\ D.M. Stafford Smith ${ }^{\mathrm{a}, \mathrm{g}}$, D. Rockstroh ${ }^{\mathrm{a}, \mathrm{h}}$, M. LaFlamme ${ }^{\mathrm{a}, \mathrm{d}}$, M. Young ${ }^{\mathrm{i}}$, M.F. Rola-Rubzen ${ }^{\mathrm{a}, \mathrm{j}}$ \\ ${ }^{a}$ Desert Knowledge Cooperative Research Centre, Alice Springs, NT 0871, Australia \\ ${ }^{\mathrm{b}}$ CSIRO, Ecosystem Sciences, PO Box 2583 Brisbane, QLD 4001, Australia \\ ${ }^{\mathrm{c}}$ National Centre for Indigenous Studies, Australian National University, Canberra, ACT 0200, Australia \\ d CSIRO, Ecosystem Sciences, PO Box 2111, Alice Springs, NT 0871, Australia \\ e Centre for Rural Health and Community Development, University of South Australia, Whyalla, SA 5608, Australia \\ ${ }^{\mathrm{f}}$ School for Social Policy \& Research, Charles Darwin University, Darwin, NT 0909, Australia \\ ${ }^{\mathrm{g}}$ CSIRO, Ecosystem Sciences, PO Box 284, Canberra, ACT 2602, Australia \\ ${ }^{\mathrm{h}}$ School of Tourism and Hospitality Management, Southern Cross University, Coffs Harbour, NSW 2457, Australia \\ ${ }^{i}$ Centre for Appropriate Technology, PO Box 8044, Alice Springs, NT 0871, Australia \\ ${ }^{j}$ School of Agriculture and Environment, Curtin University, GPO Box U1987, Perth, WA 6845, Australia
}

\section{A R T I C L E I N F O}

\section{Article history:}

Received 16 December 2009

Received in revised form

18 May 2010

Accepted 21 September 2010

Available online 15 October 2010

\section{Keywords:}

Arid

Institutions

Norms

Rangelands

Social networks

Weak ties

Wiry ties

\begin{abstract}
A B S T R A C T
Social actors in arid regions must develop strategies to respond to available resources, which are scarce, variable, patchy and unpredictable relative to other regions. We explore our observations of relationships amongst people and organisations in Australian deserts using a stylised network model of the structure of social networks in arid systems. Results suggest that temporal resource variability drives increased network density, but with fewer strong ties; sparse populations drive a relatively higher proportion of strong ties, and that networks develop a hub configuration as resource endowments become more patchy spatially. These ideas highlight some issues that warrant improved understanding by actors seeking to enhance livelihoods and local resilience in these extreme environments.
\end{abstract}

Crown Copyright $\odot 2010$ Published by Elsevier Ltd. All rights reserved.

\section{Introduction}

As new analytical methods emerge (e.g. Danon et al., 2005; Fan et al., 2007; Newman and Leicht, 2007), thinking about social network structures that were historically rooted in sociology, economics (see Watts, 2003) and to some degree physics, are being developed and applied to interdisciplinary problems. For many such problems, case studies point to the importance of network structure in how resources are (or are not) mobilised and shared (e.g. Ernstson et al., 2008; Ramirez-Sanchez and Pinkerton, 2009). Arid resources can be scarce, variable, patchy and unpredictable relative to other regions. Hence understanding the networks of arid communities, and how these are shaped by their arid contexts, is

\footnotetext{
* Corresponding author. CSIRO, Ecosystem Sciences, PO Box 2583 Brisbane, QLD 4001, Australia. Tel.: +61 732142359.

E-mail address: ryan.mcallister@csiro.au (R.R.J. McAllister).
}

critical for combating desertification, building livelihoods and managing natural resources.

Here, a network is defined as the emergent structure that arises from the behaviour of individual 'nodes' and how they connect to one another in the transfer of resources. In this context, nodes may be individual humans or other organisms, social groups like families or communities, or formal organisations like businesses, government agencies or non-government bodies. Networks provide the architecture through which information spreads, markets operate and people render assistance to each other to 'get ahead' or 'get by'. Not only are network structures shaped by the behaviour of their nodes, but the emergent network structure enables and constrains that behaviour (Giddens, 1984).

Social network analysis can provide quantitative measures of complex system function. It has particular value in promoting rigour and new insights into the often vague concept of social capital (Burt, 2005). Analysis of social networks can identify levers 
that can be used to influence the function of complex socialecological systems. The motivation for understanding social networks therefore extends beyond an academic interest. For example it is important where governments are seeking to enhance people's capacity to access resources or to apply resources to a collective goal. It is also important for businesses that want to expand market reach, particularly in isolated regions.

Arid social-ecological systems are characterised by a distinctive mix of driving forces that focus attention on aspects of networks which are less prominent in other systems. Ecologically, arid environments mostly experience low levels of primary productivity and highly variable rainfall patterns. Socially, their communities tend to be sparse, mobile, and remote from economic and political opportunities. These factors interact with the ecology to drive further variability in social and economic domains. One key human response is mobility (Butt, 2010; McAllister, 2010; Taylor et al., 2006), both within arid regions and between arid and more humid regions, which generates further variability. Sedentarisation of livestock herders, whether driven by policies that restrict mobility or by household investments in improving their access to scarce resources (e.g. Sternberg, 2008), demonstrates how social and ecological drivers, and networks co-evolve.

The causal chain of arid drivers can be viewed as a 'syndrome' (Stafford Smith, 2008) which leaves its mark throughout arid systems, in the particular suite of plant and animal life histories (Chesson et al., 2004; Stafford Smith and McAllister, 2008), in human settlement patterns and service delivery models (Long, 1971; Maru and Chewings, 2008; Stafford Smith et al., 2008), and options for businesses (e.g. Taylor et al., 2008). Here we explore the impact of individual drivers on arid networks, contributing more generally to an understanding of system complexity along gradients of sparseness in population from remote to urban and variability in resources from arid to humid.

By 'arid networks' we mean networks based in arid regions and responding to resources that are scarce and also highly unpredictable in both space and time ("scarce, variable and patchy"), whether these resources are biophysical (e.g. rainfall, soil nutrients), social (e.g. people, skills) or economic (e.g. capital, market opportunities). The main literature relevant to the structural characteristics of arid networks is sociological research focused on rural networks. Beggs et al. (1996) proposed that rural, social systems are likely to foster small-dense networks where nodes have multiple roles. Entwisle et al. (2007) draw on their extensive data on rural networks in Thailand to show that network structures are dependant on their context. Isaac et al. (2007) find a core-periphery structure in agroforestry advice networks in Ghana. Arid systems are less productive than other rural regions, by definition, and hence are likely to have populations which structure differently.

Literature specifically about the effects of arid geography on networks is sparse. A recent review presented hypotheses about the characteristics of contemporary social networks in Australian arid regions, suggesting they tend to be tightly bound, to be hierarchical in structure and hence prone to power abuses, and to contain a relatively high proportion of weak ties which can be mobilised in crises (see McAllister et al., 2008). Additionally, there is a rich stock of ethnographic accounts. While these are not framed within network theory, they provide compelling evidence of the ways in which resource distribution in arid systems is managed through a range of highly adaptive networks. Ethnographic evidence from desert Australian Aboriginal social structures indicates that arid cultures with small populations benefit from flexible leadership and rapid exchange of ideas, but conversely also suffer from the potential for nepotism and corruption, and the dominance by 'big men' with resource limitations increasing the competition for scarce resources (see Holcombe, 2004, 2005; Meggitt, 1962; Myers, 1986; Peterson, 1975, 2000).

This paper uses a stylised model which generalises network formation across sectors (economics, society, business, ecology), with a focus on features relevant to network responses to the scarce, variable and patchy resources characteristic of arid regions. The model is then analysed to explore how network structure is affected by changing levels of resource scarcity, and of spatial and temporal variability in the resources as experienced by individual nodes. The aim is to better understand the likely structures of networks influenced by these arid system characteristics. The resulting networks could have implications for different forms of business networks (e.g. mining services companies concentrated on occasional large business opportunities compared to tourism networks focused on many small opportunities; cf Taylor et al., 2008), networks among pastoralists (i.e. herders, graziers, e.g. exchanged grazing rights, see Reeson et al., 2008), or Aboriginal social networks today. The paper concludes by discussing some implications of arid network structures for policy and management aimed at improving the livelihoods of those who live in arid regions.

\section{Conceptualising arid networks}

In framing problems networks need to be carefully defined. The building blocks for a network are its nodes (the entities in the system) and ties (the links between nodes). Clear rules about what constitutes a node need to be established, as do rules that establish what defines a tie between two nodes and also the strength of the ties.

The idea of tie strength is particularly relevant to resource distribution in arid systems. The theory of the "strength of weak ties' holds that weak ties can be more efficient than strong ties in gaining resources like key pieces of information and business opportunities (see Granovetter, 1983 for a review, and Granovetter, 1973 for original text). ${ }^{1}$ This is particularly relevant where resources are heterogeneous: Ties between nodes within a dense cluster tend to be relatively strong. This is what gives the cluster its cohesion, but also means that the nodes within the cluster are accessing the same set or source of resources. Any nodes that have ties to other nodes outside that dense cluster have access to different resource concentrations. Such ties do tend to be weaker since strong ties act to 'pull' the outside nodes into being part of the dense cluster. Burt (2004) develops such ideas in detail, describing how 'broker' nodes bridge 'structural holes' between relatively 'closed' (dense) networks.

The implications of the mix of weak and strong ties depend on the context (e.g. see Fritsch and Kauffeld-Monz, 2010). In arid systems the relative importance of weak ties is likely to be driven by local heterogeneity of resources, leading to periods of localised resource deficiencies (McAllister et al., 2008): the more common and unpredictable local deficiencies are, the greater the number of ties required to insure against catastrophically low levels of a resource. From this discussion, it can be seen that the term 'weak tie', whilst technically correct, may be misleading in arid networks - these are ties which need to be persistent and which are also relatively cheap to maintain. Accordingly, henceforth, we use the term 'wiry tie' - lean, but efficient in the face of resource limitations.

\footnotetext{
1 These concepts are normative and may be understood quite differently by Aboriginal people. For instance, nepotism may be understood merely as entitlement, whereby a family has primary rights to an area of land and thereby its resources by virtue of inherited rights. It may just so happen that a settlement is established on this land and thus further resources are available to be monopolised.
} 
In general, existing theory suggests that reciprocity facilitated by strong ties is the priority for survival (e.g. Meert, 2000), but, as resource availability becomes less certain, weak (or wiry, as used here) ties do more to manage risk. This is because as resource variability increases, there is less chance that any strong ties will link to nodes with resources to share.

Real networks can appear to lack the clear scope and boundaries that are required by theoretical definitions: a network view can be applied to a diverse range of contexts, and there will be many interacting networks in a single system. For example, the ties through which information flows in classical central Australian Aboriginal societies also defined the network through which foods and other resources were shared (Myers, 1982). Sociologists examine the multiple roles of networks under the term 'multiplexity'. This is more likely to be an important feature of rural area networks than those in more densely settled regions where networks are able to involve different sets of people or organisations (Beggs et al., 1996). Multiplexity needs to be understood and addressed in proposing generalities based on quantitative statistics about network structure.

\section{Model}

Here we present a computational model which allows network structures to emerge from the individual decisions of many nodes. The mechanics of the model are complex, but the underpinning idea is very simple. In the model, individual nodes in a network mathematically optimise who they share resources with. This models behaviour in human societies where sharing resources may promote survival in bad times, but also involves costs. Such models do not prove anything. Rather they formalise descriptions of emergent network processes based on transparent underlying assumptions.

There is an extensive economics literature on modelling network formation (e.g. Bala and Goyal, 2000; Boorman, 1975; Jackson and Watts, 2002; Toivonen et al., 2009). Our model borrows from these more formal modelling frameworks, but is itself a simple combinatorial optimisation model, focusing on how networks respond where resources are scarce, patchy and variable, as in arid systems. Each run of the model assumes a fixed number of nodes, each having a fixed effort-budget which they can allocate to create persistent, non-decaying ties to other nodes. The model explores optimal static network structures.

Table 1

Key model assumptions (see supplementary material).

\begin{tabular}{ll}
\hline Assumption & Description \\
\hline 1 & $\begin{array}{l}\text { Nodes are non-cooperative and hence what may } \\
\text { appear to be cooperation is mutually beneficial } \\
\text { selfish behaviour } \\
\text { The resource holders endowments do not lose value when } \\
\text { shared, (e.g. knowledge, sharing, support) though its } \\
\text { value to those who acquire the resources is depreciated } \\
\text { based on the strength of the network tie to the node } \\
\text { holding the resource }\end{array}$ \\
& $\begin{array}{l}\text { Nodes maximise their median (rather than mode or mean) } \\
\text { of resources held, where the median } \\
\text { is taken overall time periods }\end{array}$ \\
& $\begin{array}{l}\text { Each node has a fixed effort-budget used for maintaining } \\
\text { ties to other nodes } \\
\text { The allocation of effort used for maintaining ties is constant } \\
\text { across all time periods in the model } \\
\text { Each model received the same total (but not distribution) } \\
\text { of resources in each run of the model } \\
\text { A strong tie is defined as a link (tie) between any } \\
\text { two nodes where the allocation of effort is more than } \\
\text { one-third of the maximum possible allocation. }\end{array}$ \\
&
\end{tabular}

The network is formed by nodes making individual (non-cooperative, see Bala and Goyal, 2000; Assumption 1, Table 1) choices about which ties to invest in, given that the effectiveness of their investment is affected by the investments of all other nodes. Resources are injected into nodes probabilistically, providing them with direct benefits, and there are indirect benefits to other nodes as resources flow via the network's ties. The degree to which resources flow through the network ties is based on the strength of relationships between nodes. Once a node has obtained resources, those resources depreciate over time. We also assume that the resources shared do not lose value (e.g. sharing knowledge or equipment, or offering support) and hence sharing the resource does not reduce the resources of any individual (Assumption 2). The problem for each node is therefore how to allocate its networking efforts to maximise its median expected resources held over time (Assumption 3).

An important concept in terms of interpreting the model is that we do not analyse the material flow of goods, knowledge and other resources, but rather the ties that facilitate flows through the network. The main advantage is that the structure is likely, conceptually at least, to provide more general insights than material flows alone; in particular aspects of human reciprocity can result in important ties that may not result in bilateral material flows (see Fig. 1; Schaniel and Neale, 2000). Further, the assumptions we use are largely consistent with knowledge flows (particularly Assumption 2), but by looking very generally at how networks form in response to resource availability, we assert that the relationship between the results and drivers holds lessons that are general enough to inform a range of topics. In addition, in the Appendix (supplementary material) we relax some assumptions (including Assumption 2). This confirms that assumption parameter selection does not change the general implications of the model. While we base our assumptions on our expert knowledge of arid systems, the implications are broadly applicable to networks elsewhere that are faced with similar drivers.

\subsection{Descriptive measures of network structure}

This model produces networks which are defined by the allocations of the effort-budget towards network ties across all nodes; these patterns then require interpretation. Some modelling exercises have defined weak ties as those where only one of two nodes allocate effort towards the tie (e.g. Boorman, 1975), but this approach is incompatible with the current model which assumes a tie will only be active when both nodes allocate effort (see supplementary material). Hence we define a strong tie as one where the allocation is more than one-third of the maximum possible allocation to that tie (Assumption 7). All other ties (where both nodes allocate effort) are defined as wiry ties, the term we introduce above to signify ties that, while weak, may be efficient in their arid context.

Path length is defined as the number of intermediate nodes along the shortest path between any two nodes. Network density is defined as the number of connections (either wiry or strong) in the network as a percent of all possible connections. Clustering measures how cliquey a network is, as the likelihood that the nodes connected to a node are themselves connected. The weighted clustering coefficient calculates this for networks with ties of varying strengths (see Barrat et al., 2004; Barthelemy et al., 2005) and where $\tau$ (see Equation (1) in supplementary material) is used to define the weights of the network ties. We use the Boost library algorithm (Gleich, 2007). Finally, centrality measures how important key nodes are in the system. There are many concepts and measures of centrality; we use betweenness centrality (see Freeman, 1977, 1978) with $\tau$ used to define the strength of ties, again applying the Boost library algorithms (Gleich, 2007), though 
a
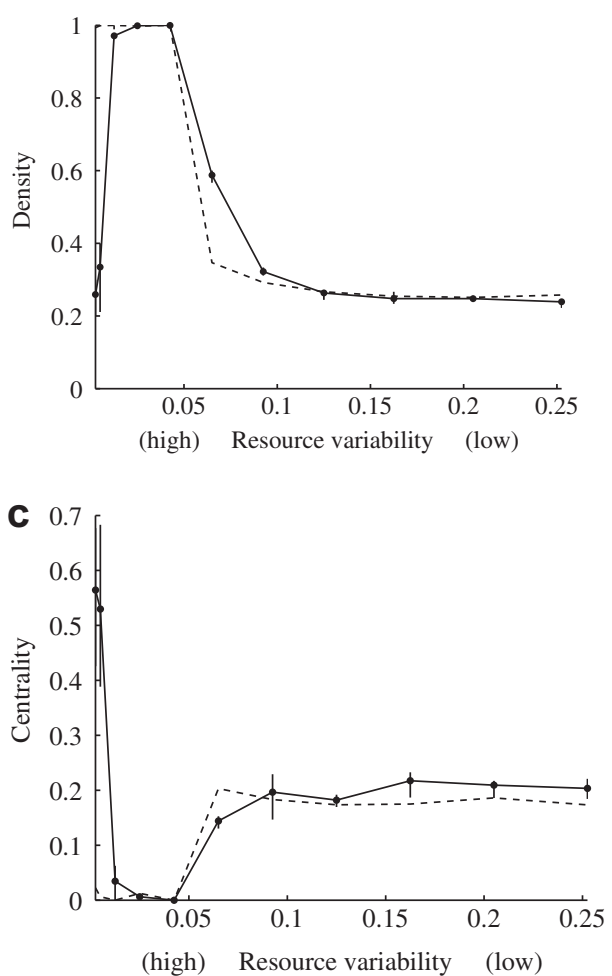

e
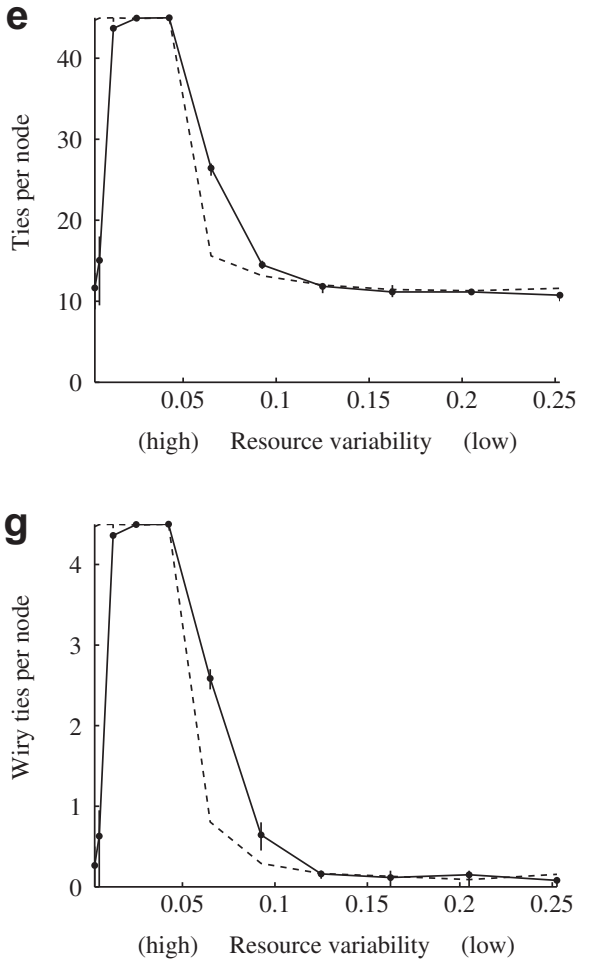
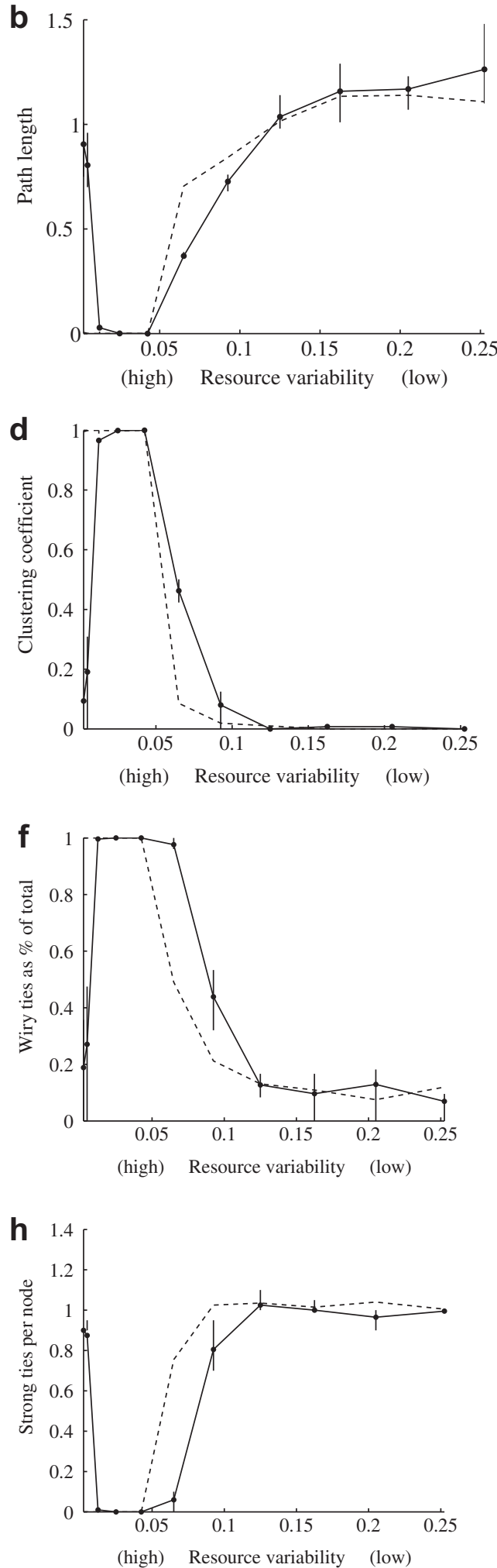

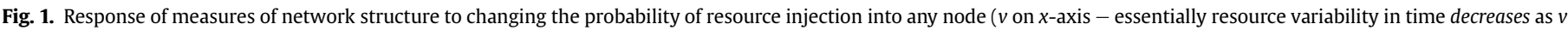

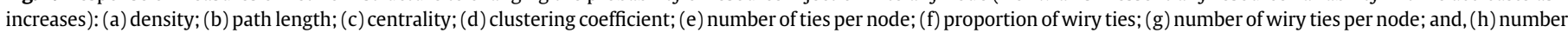

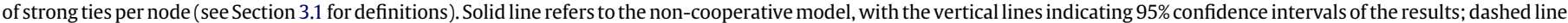
refers to the alternative cooperative model (see Section 4.4). Twenty-five percentile ranges are used in graphs to show the spread of the results across the 20 runs.

we present a node's betweenness centrality as a percentage of the sum of the betweenness centrality of all nodes for a given network.

Model experiments used these network measures to explore key arid drivers and model sensitivity to some assumptions. Each treatment was replicated 20 times with different random seeds. Not only does each of the 20 runs have a different resource distribution, but even the same resource distribution would produce different networks because the satisficing solutions are quite path 
dependant. In the figures, average results are presented and twenty-five percentile ranges are used to show the spread of the results across the 20 runs.

For further model details, including all equations, see Appendix (supplementary material).

\section{Results}

\subsection{The effect of changing temporal resource variability}

A sensitivity analysis was conducted on the probability of resource injection into nodes (Figs. 1 and 2). This tests the effect on network structures of changing the arid system driver of patchiness over time. Complicated but explicable behaviour emerged. Low probabilities of resource injection (i.e. high levels of variability) were associated with a high proportion of wiry ties. At both extremes of variability strong ties are more common relative to wiry ties. However, networks under extreme low variability were distinguished from those under high variability by their betweenness centrality. At extremely high variability (low $v$, see supplementary material for more details on model terms), the network is very centralised with strong ties associated with the formation of a hub configuration. From there, even slight decreases in variability (increases in $v$ ) quickly lead to the formation of networks with low centrality (Fig. 1c), dominated by nodes with a diverse spread of wiry ties (Fig. 1g). As variability decreases further, strong ties again grow in proportion, but centrality never reaches the levels associated with extreme variability. This is because these strong ties are indicative of strong reciprocal relationships rather than a hub configuration (Fig. 2). However, the level of extreme variability applied here is probably unrealistic.

Summary I: Increasing resource variability over time drives networks to be relatively more densely connected, but with a greater proportion of wiry ties.

\subsection{The effect of the number of nodes}

Arid systems tend to contain relatively fewer actors than others. To explore this we tested how network structures changed with the numbers of nodes $N$, relative to the base value of 10 . As the number of nodes in the system decreases, from 25 down to and below the base value of 10, the number of ties per node decreases (Fig. 3e). Down to $N=8$, the decrease in the number of ties is as a result of fewer wiry ties and in fact the number of strong ties increases slightly (Fig. $3 \mathrm{~g}$ and f). Below $N=8$, the trend reverses. However, network density increases consistently in smaller networks (Fig. 3a), meaning that node ties expressed as a percentage of the total possible ties increases (now from fewer options) as node numbers decrease. Small networks also have high centrality (Fig. 3c).

Summary II: Smaller networks have a greater proportion of strong ties.

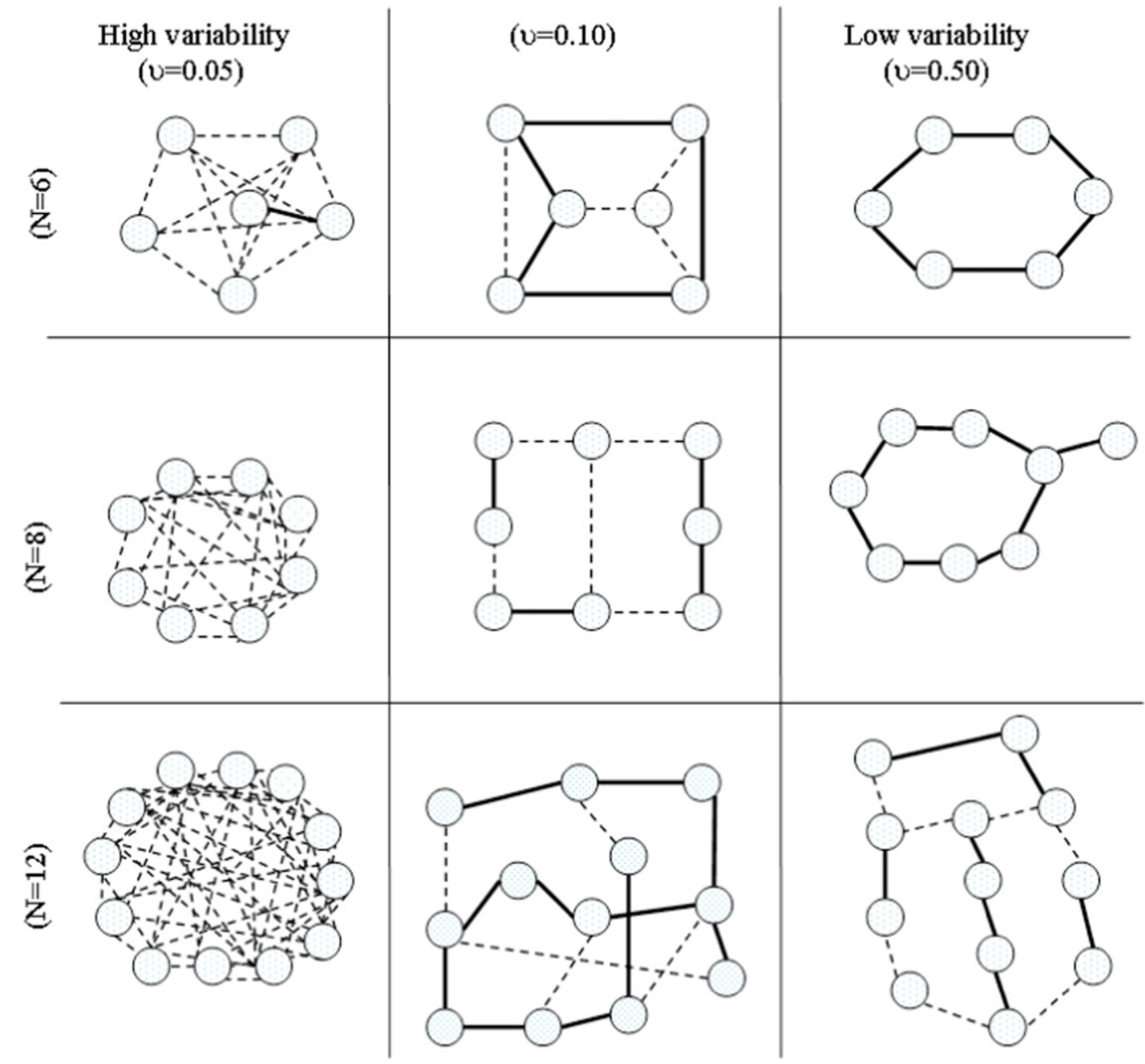

Fig. 2. Example networks showing degrees of resource variability and various network sizes (with base assumptions). Solid and dashed lines indicate strong and wiry ties. 

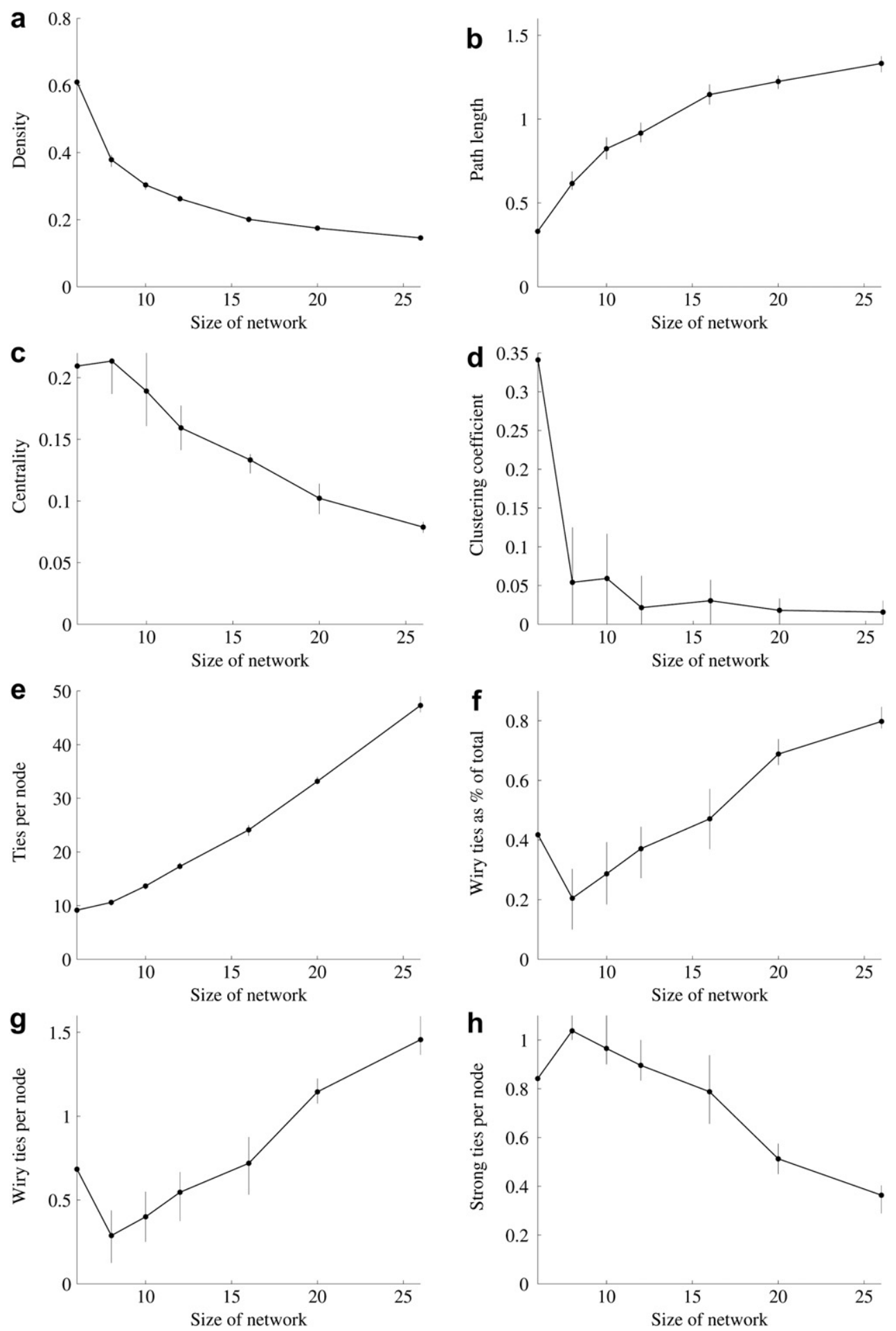

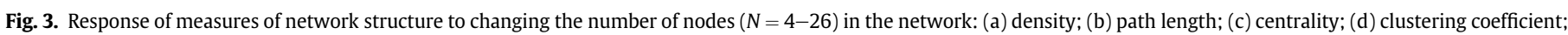

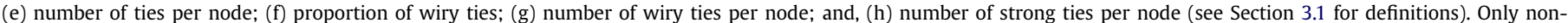
cooperative model results shown.

\subsection{The effect of changing the patchiness of spatial resources}

Arid systems tend to have resources that are clumped in space. The base model assumes that all nodes have an equal probability of being endowed with resources in any given time period (Assumption 6, Table 1). This assumption is now relaxed to examine the impact of spatial patchiness by picking one focal node for which the scale of the resource endowment is increased, whilst maintaining the same probability of a node receiving a resource endowment. Scaling up resources for a focal node increases network centrality (Fig. 4c), and reduces network density as a result of a decrease in wiry ties (Fig. 4a and f). Visually, this gives rise to hubs or hub configurations (Fig. 5). 
Summary III: Networks with consistently advantaged nodes are likely to develop a hub configuration.

\subsection{Cooperative and non-cooperative networks compared}

As noted (Assumption 1), the model as described assumes noncooperative decision making, such that individual node's choices
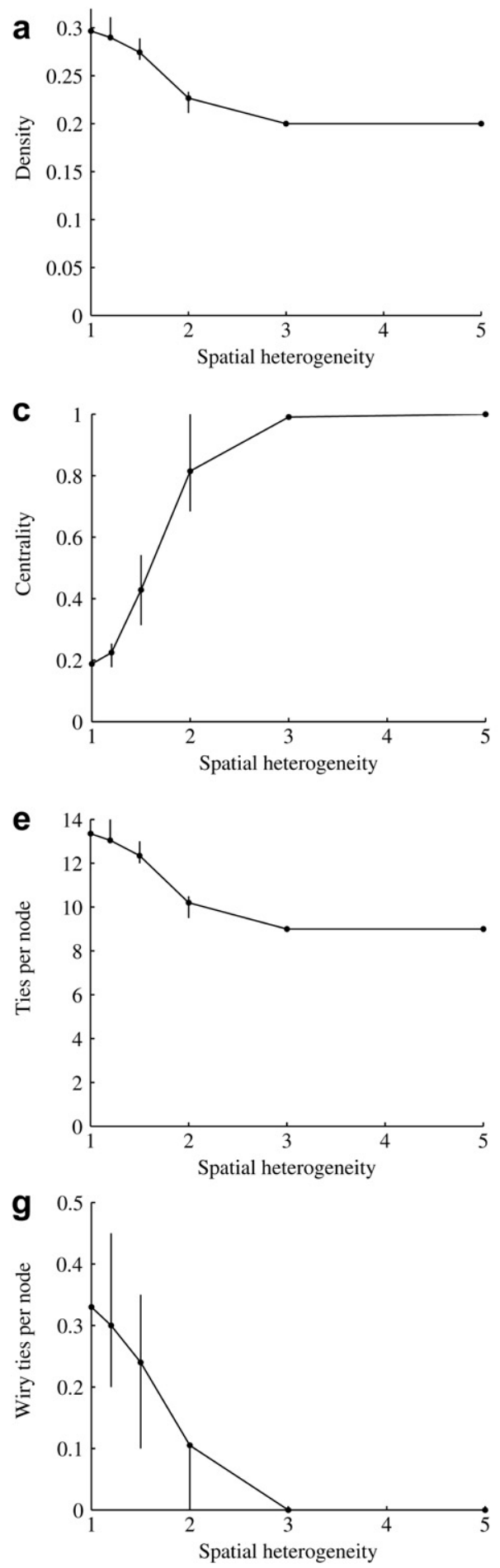

can decrease the overall network payoff. However, some networks may be affected by strong social norms which promote cooperative behaviour. To test the impact of this assumption on the generality of the results, a cooperative optimisation algorithm was applied (i.e. in general, nodes' decisions must increase the whole network payoff).

Differences between the cooperative and non-cooperative models were too slight to draw strong conclusions (Fig. 1), but one feature is worthy of comment. At intermediate levels of temporal
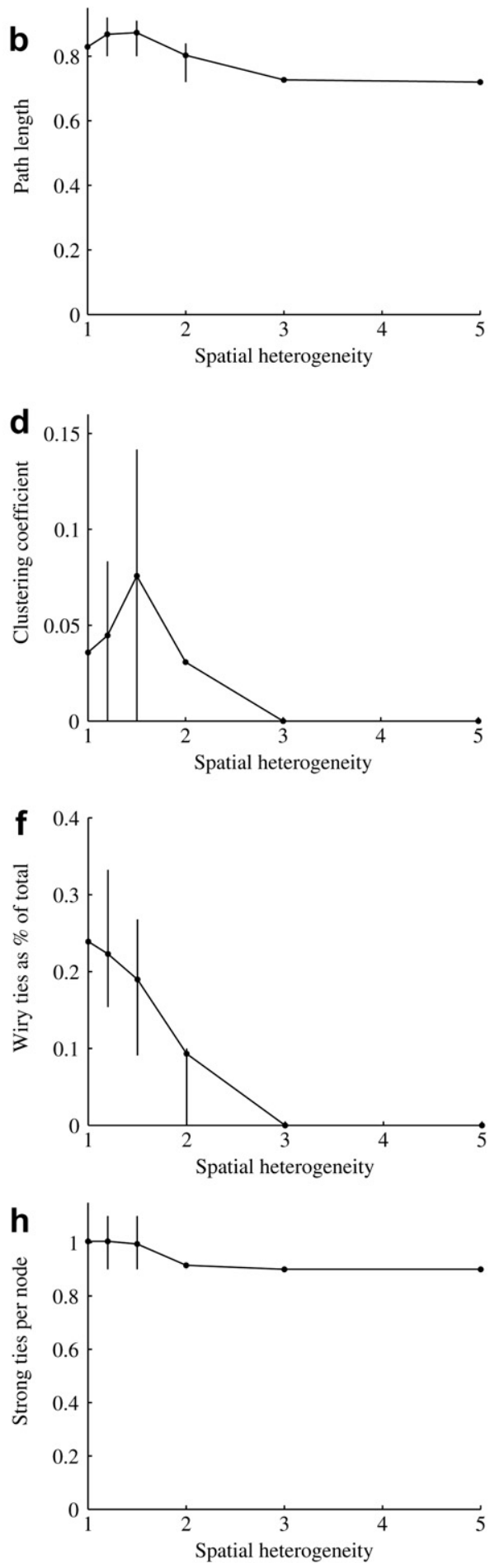

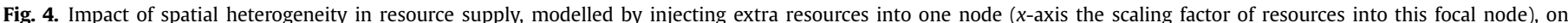

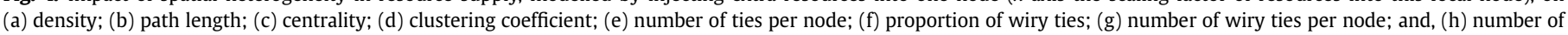
strong ties per node (see Section 3.1 for definitions). 


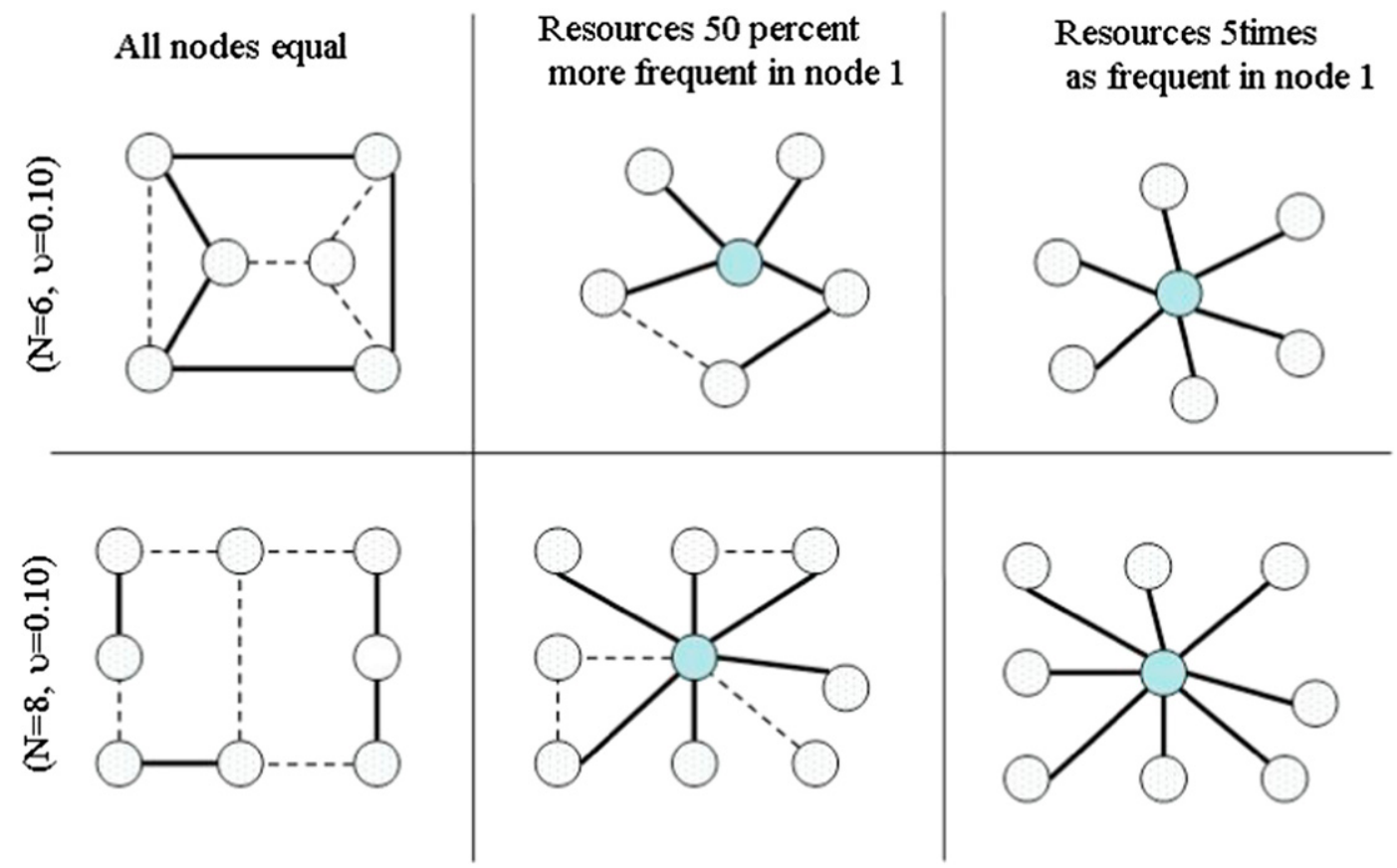

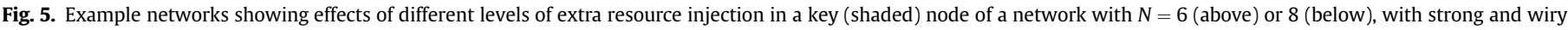
ties indicated by solid and dashed lines.

variability $(v \sim 0.1)$ the conformity in the density and total number of ties masks differences in the mix of wiry and strong ties. The cooperative model networks favour strong ties over wiry when compared to the non-cooperative networks.

\section{Implications for policy and management}

Policy makers seeking to improve the livelihoods of desert dwellers need identifiable policy levers. This paper presents ideas rather than prescription, and strong policy guidance needs strongly contextualised studies. However the findings of this paper suggest some framework issues for policy action which deserve further testing. Here policy implications are explored in the context of arid Australia.

Recent practitioner literature from Australia argues that better networking, higher bridging social capital and increased critical mass are important for improving outcomes for those entities involved in the network (e.g. Brown, 2000; Enright and Roberts, 2001; Hunt and Smith, 2007; Measham and Brake, 2009). However, the model shows that the effects of temporal variability in resources and numbers of nodes generate tensions on idealised network architecture. People and organisations in arid regions are limited in the number of ties that they can readily make by sparse populations. The model predicts that the small population of arid regions creates an impulse that is contrary to the drive from variability towards more diverse ties, driving nodes to favour fewer but stronger ties.

The model suggests that the balance between strong and wiry ties is quite complex, explaining the dissonance expressed by McAllister et al. (2008) where arid networks were both seen to possess extensive wiry ties, yet to be exemplified by powerful reciprocal obligations in Aboriginal group (e.g. Keen, 2004; Strehlow, 1970) and pastoral societies (see McAllister et al., 2006).

The diversity of tie strengths is supported by the work on business clustering by Taylor et al. (2008) (see Stafford Smith and Cribb, 2009). They found that mining services companies rapidly created strong network relationships compared to the wider diffuse networks of the tourist and outback foods industries, and the smaller weaker networks among outback architects. Mining services companies are responding to variable, large resource inputs (in the form of contracting opportunities with large mining companies). Strong ties were vital to allow a number of relatively small companies to scale up to the capacity required to deliver on these contracting opportunities. In contrast, whilst resource inputs were also variable for the tourist industry (varying tourist demand through time and across different destinations geographically), there are many more players who are each able to access some resource inputs (tourists) without the costs involved in establishing strong ties. The moderate numbers of strong ties that formed in the mining services cluster thus contrasted with the diffuse wiry ties in tourism (which probably also had more of a hub configuration with some large companies and major tourism sites such as Uluru) in ways which correspond the model outcomes.

The implications of network structures in arid Australia can be condensed into three key lessons; all of which may be applicable not only outside of Australia, but also in non-arid networks exposed to similar drivers.

\subsection{Reduce the transaction costs involved in establishing wiry ties}

Whether the nodes are people, businesses or organisations, there are transaction costs incurred by nodes in creating and maintaining ties (Gordon, 1994). Reducing such transaction costs can allow nodes to make better use of ties and improve the efficiency of the 'market'. This idea is widely entrenched in economics, as is the idea that networks which link supply and demand form economic markets and development (e.g. Crowe, 2007; Granovetter, 2005). However, the implication in arid systems is that novel solutions to reducing transaction costs are required to overcome the sparseness and mobility of their human populations. For example, 'Desert Knowledge Australia' works towards establishing business clusters in arid Australia, activities that effectively 
subsidise the costs of learning how to use cutting edge telecommunications and teleconferencing facilities for business (Taylor et al., 2008). Such approaches take new global technologies and adapt them to deal with the transaction costs that are particularly relevant to arid systems. Researchers also have been exploring technological solutions to reduce networking transactions costs in semi-arid pastoral systems (Reeson et al., 2008). Fostering social norms that then facilitate the efficient activation of wiry ties when needed is another means to reducing transaction costs. There are numerous examples of activities that build positive social norms such as dustWatch (Leys et al., 2008), Warlpiri radio (Hinkson, 2004), and sport (e.g. Tonts, 2005).

\subsection{Expect and manage for dense, hubbed networks}

Understanding hubs is an important issue because they are often implicated in network designs (e.g. innovation clusters, see Fromhold-Eisebith and Eisebith, 2005). As we have shown, local networks are likely to be dense with strong ties, and will often evolve to have hubs in arid regions. These provide both benefits and threats to institutional structures. Benefits include the opportunity for strong leaders to act effectively and flexibly, and it is particularly important to support those leaders actively in arid areas - this is also a major finding of research on institutions among natural resource management (Measham and Brake, 2009) and among contemporary Aboriginal governance structures (Hunt and Smith, 2007). Threats include the natural tendency for power to accumulate with a few people who have strong reciprocal obligations to their immediate network, such that there is a high risk of nepotism and abuse of power. There is no point pretending this will not happen - it is a natural outcome of this type of network - so it is important to establish and support effective mechanisms of downwards accountability which do not depend solely on the informal social networks (see, for example, Moran and Elvin, 2009). By accepting the risks, the goal here is to consciously act to minimise the bad effects whilst maximising the good ones.

\subsection{Work with the diversity of arid networks to increase local resilience}

Local resilience to crises will depend on institutions and individuals that can activate wiry ties in flexible ways. Distant legislation or policy that forces particular structures on arid networks (formal or informal) is likely to create sub-optimal responses. For example, many arid institutions acquire local flexibility. Yet centralised decisions tend to reduce overlapping capacities, while degrading the ability of institutions to work together in unpredictable, unknowable teams in times of crisis. An example is the recent amalgamation of local government in central Australia. The aim is to improve economies of scale, but aiming for economies of scope may be a better, more flexible goal (see Campbell et al., 2008; Dollery and Fleming, 2005; Stafford Smith and Cribb 2009). Ultimately, the success of these new governance arrangements will depend on how economies of scope and scale interact with and respond to issues and needs as they arise in multiple small scale and diverse local contexts.

Meanwhile spontaneous (but temporary) local coordination occurs among local government, natural resource groups and regional development bodies (Measham and Brake, 2009). This creates innovative solutions to the region's problems that would be unlikely to emerge from a legislated requirement for these bodies to cooperate. In short, institutions in arid systems may need to be constructed with overlapping functionality and facilitated to work jointly on crisis issues.
All these proposals are offered in the form of plausible hypotheses that emerge from the convergence between our simple network model and observations of reality in arid regions. These in turn thus create hypotheses that now require further testing and elaboration in the field.

\section{Conclusion}

Arid systems are characterised by high variability in resource supply in time and space, and sparse populations (and consequently also sparse institutions), all relative to less arid systems. Because arid systems are exposed to extremes, they provide an excellent case into how context shapes networks. Here a model is used to structure hypotheses about how arid characteristics shape networks. While we focus on arid systems, the model holds for all networks exposed to key drivers in arid systems, variability of resources in particular.

A simple, stylised network model, where nodes make optimal investments in ties to other nodes in order to share or trade resources supplied with different degrees of variability in time and space, showed that: (I) Increasing resource variability over time drives networks to be relatively more densely connected, but with a greater proportion of wiry ties; (II) Smaller networks have a greater proportion of strong ties; (III) Networks with consistently advantaged nodes are likely to develop a hub configuration. In general, these findings are supported by and provide an explanation for observations about the characteristics of contemporary Australian arid social networks, although the characteristics of strong and wiry ties need further elaboration. We have also explicitly identified a variety of simplifying assumptions in the model as presented in Table 1, and these also deserve further exploration.

We conclude that arid networks are likely to show significantly different characteristics to those of less arid regions, warranting further investigation in terms of the implications for models of institutional arrangements, service delivery and governance in these regions. In particular, the model results suggest that governments concerned to promote self-reliant habitation and management in sparsely populated arid regions should: (i) invest to reduce the costs of developing and sustaining wiry ties within the region and to the outside; (ii) recognise that dense, hubbed networks are likely to develop naturally in arid regions, providing both benefits (good leadership and fast adaptability) to be promoted and risks (centralised power, corruption and nepotism) that should be explicitly guarded against; and (iii) increase local resilience to crises by facilitating flexible networking and durable wiry ties among overlapping local institutions, rather than amalgamating and homogenising institutions in ways that disrupt the natural development of effective arid networks.

\section{Acknowledgements}

This paper emerged from a workshop run by Ryan McAllister as part of the Desert Knowledge CRC funded project, the Science of Desert Living. Many thanks to other workshop participants, and to Andrew Higgins, Tom Measham and two anonymous reviewers for critical comments. The model in this paper is the responsibility of the lead author, with the remaining authors contributing the contextual underpinnings of the model, text and case knowledge. Much of the work reported here was supported by funding from the Australian Government Cooperative Research Centres Programme through the Desert Knowledge CRC; the views expressed herein do not necessarily represent the views of Desert Knowledge CRC or its participants. This is Publication No.5 in the development of a Science of Desert Living. 


\section{Appendix. Supplementary material}

Supplementary data related to this article can be found online at doi:10.1016/j.jaridenv.2010.09.009.

\section{References}

Bala, V., Goyal, S., 2000. A noncooperative model of network formation. Econometrica 68, 1181-1229.

Barrat, A., Barthelemy, M., Pastor-Satorras, R., Vespignani, A., 2004. The architecture of complex weighted networks. Proceedings of the National Academy of Sciences of the United States of America 101, 3747-3752.

Barthelemy, M., Barrat, A., Pastor-Satorras, R., Vespignani, A., 2005. Characterization and modeling of weighted networks. Physica A-Statistical Mechanics and Its Applications 346, 34-43.

Beggs, J.J., Haines, V.A., Hurlbert, J.S., 1996. Revisiting the rural-urban contrast: personal networks in nonmetropolitan and metropolitan settings. Rural Sociology $61,306-325$

Boorman, S.A., 1975. A combinatorial optimization model for transmission of job information through contact networks. Bell Journal of Economics 6, 216-249.

Brown, R., 2000. Clusters, Innovation and Investment: Building Global Supply Chains in the New Economy. Australian Project Development Pty Ltd, Canberra.

Burt, R.S., 2004. Structural holes and good ideas. American Journal of Sociology 110 , 349-399.

Burt, R.S., 2005. Brokerage and Closure: An Introduction to Social Capital. Oxford University Press, Oxford, UK.

Butt, B., 2010. Seasonal space-time dynamics of cattle behavior and mobility among Maasai pastoralists in semi-arid Kenya. Journal of Arid Environments 74, 403-413.

Campbell, D., Davies, J., Wakerman, J., 2008. Facilitating complementary inputs and scoping economies in the joint supply of health and environmental services in aboriginal central Australia. Rural and Remote Health 8 (Online).

Chesson, P., Gebauer, R.L.E., Schwinning, S., Huntly, N., Wiegand, K., Ernest, M.S.K. Sher, A., Novoplansky, A., Weltzin, J.F., 2004. Resource pulses, species interactions, and diversity maintenance in arid and semi-arid environments. Oecologia 141, 236-253.

Crowe, J.A., 2007. In search of a happy medium: how the structure of interorganizational networks influence community economic development strategies. Social Networks 29, 469-488.

Danon, L., Diaz-Guilera, A., Duch, J., Arenas, A., 2005. Comparing community structure identification. Journal of Statistical Mechanics:Theory and Experimen 2005.

Dollery, B.E., Fleming, E., 2005. A Conceptual Note on Scale Economies, Size Economies and Scope Economies in Australian Local Government. University of New England, School of Economics, Armidale.

Enright, M.J., Roberts, B.H., 2001. Regional clustering in Australia. Australian Journal of Management 26, 65-86.

Entwisle, B., Faust, K., Rindfuss, R.R., Kaneda, T., 2007. Networks and contexts: variation in the structure of social ties. American Journal of Sociology 112, 1495-1533.

Ernstson, H., Sorlin, S., Elmqvist, T., 2008. Social movements and ecosystem services-the role of social network structure in protecting and managing urban green areas in Stockholm. Ecology and Society 13.

Fan, Y., Li, M.H., Zhang, P., Wu, J.S., Di, Z.R., 2007. Accuracy and precision of methods for community identification in weighted networks. Physica A-Statistical Mechanics and Its Applications 377.

Freeman, L.C., 1977. A set of measures of centrality based on betweenness. Sociometry 40.

Freeman, L.C., 1978. Centrality in social networks: conceptual clarification. Social Networks 79, 215-239.

Fritsch, M., Kauffeld-Monz, M., 2010. The impact of network structure on knowledge transfer: an application of social network analysis in the context of regional innovation networks. Annals of Regional Science 44, 21-38.

Fromhold-Eisebith, M., Eisebith, G., 2005. How to institutionalize innovative clusters? comparing explicit top-down and implicit bottom-up approaches. Research Policy 34, 1250-1268.

Giddens, A., 1984. The Constitution of Society: Outline of the Theory of Structuration. Polity Press, Cambridge.

Gleich, D., 2007. Matlab boost graph library v2.1. http://www.boost.org/doc/graph.

Gordon, R.L., 1994. Regulation and Economic Analysis: A Crique over Two Centuries Kluwer Academic Publishers, Dordrecht.

Granovetter, M., 1983. The strength of weak ties: a network theory revisited. Sociological Theory 1, 201-233.

Granovetter, M., 2005. The impact of social structure on economic outcomes Journal of Economic Perspectives 19, 33-50.

Granovetter, M.S., 1973. The strength of weak ties. American Journal of Sociology 78, $1360-1380$.

Hinkson, M., 2004. What's in a dedication? On being a Warlpiri DJ. The Australian Journal of Anthropology 15, 143-162.

Holcombe, S., 2004. Socio-political Perspectives on Localism and Regionalism in the Pintupi Luritja Region of Central Australia: Implications for Service Delivery and Governance. Australian National University, Canberra.

Holcombe, S., 2005. Luritja management of the State. Oceania 75, 222-233.
Hunt, J., Smith, D., 2007. Indigenous Community Governance Project: Year Two Research Findings. Australian National University, Canberra.

Isaac, M.E., Erickson, B.H., Quashie-Sam, S.J., Timmer, V.R., 2007. Transfer of knowledge on agroforestry management practices: the structure of farmer advice networks. Ecology and Society $12,13$.

Jackson, M.O., Watts, A., 2002. The evolution of social and economic networks. Journal of Economic Theory 106, 265-295.

Keen, I., 2004. Aboriginal Economy and Society: Australia at the Threshold of Colonisation. Oxford University Press, Melbourne.

Leys, J., McTainsh, G.H., Strong, C., Heidenreich, S., Biesaga, K., 2008. Dustwatch: using community networks to improve wind erosion monitoring in Australia. Earth Surface Processes and Landforms 33, 1912-1926.

Long, J., 1971. Arid region Aborigines: the Pintupi. In: Mulvaney, D.J., Golson, J. (Eds.), Aboriginal Man and Environment in Australia. ANU Press, Canberra.

Maru, Y.T., Chewings, V., 2008. How can we identify socio-regions in rangelands of Australia. The Rangeland Journal 30, 45-53.

McAllister, R.R.J., 2010. Livestock mobility in arid and semi-arid Australia: escaping variability in space. Pastoralism 1, 38-55.

McAllister, R.R.J., Cheers, B., Darbas, T., Davies, J., Richards, C., Robinson, C.J., Ashley, M., Fernando, D., Maru, Y.T., 2008. Social networks in arid Australia: a review of concepts and evidence. The Rangeland Journal 30,167-176.

McAllister, R.R.J., Gordon, I.J., Janssen, M.A., Abel, N., 2006. Pastoralists' responses to variation of rangeland resources in time and space. Ecological Applications 16, $572-583$.

Measham, T.G., Brake, L. (Eds.), 2009. People, Communities and Economies of the Lake Eyre Basin. Research Report 45, Desert Knowledge. CRC, Alice Springs.

Meert, H., 2000. Rural community life and the importance of reciprocal survival strategies. Sociologia Ruralis 40, 319-338.

Meggitt, M., 1962. Desert People: A Study of the Walbiri Aborigines of Central Australia. Angus and Robertson, Sydney.

Moran, M., Elvin, R., 2009. Coping with complexity: adaptive governance in desert Australia. Geojournal 74.

Myers, F., 1982. Always ask: resource use and land ownership among Pintupi Aboriginals of the Australia Western Desert. In: Williams, N., Hunn, E. (Eds.), Resource Managers: North America and Australian Hunter Gatherers. AAAS, Washington DC, pp. 173-195.

Myers, F., 1986. Pintupi Country, Pintupi self: Sentiment, Place and Politics Amongst Western Desert Aborigines. Smithsonion Institution Press, Canberra.

Newman, M.E.J., Leicht, E.A., 2007. Mixture models and exploratory analysis in networks. Proceedings of the National Academy of Sciences of the United States of America 104, 9564-9569.

Peterson, N., 1975. Hunter-gatherer territorality: the perspective from Australia. American Anthropologist 77, 53-61.

Peterson, N., 2000. An expanding aboriginal domain: mobility and the initiation journey. Oceania 70, 205-218.

Ramirez-Sanchez, S., Pinkerton, E., 2009. The impact of resource scarcity on bonding and bridging social capital: the case of Fishers' Information-Sharing Networks in Loreto, BCS, Mexico. Ecology and Society 14

Reeson, A.F., McAllister, R.R.J., Whitten, S.M., Gordon, I.J., Nicholas, M., McDouall, S.S., 2008. The agistment market in the northern Australian rangelands: failings and opportunities. The Rangeland Journal 30 , 283-289.

Schaniel, W.C., Neale, W.C., 2000. Karl Polanyi's Forms of integration as ways of mapping. Journal of Economic Issues 34, 89-104.

Stafford Smith, D.M., 2008. The 'dryland syndrome' a causal chain of factors characterising outback Australia. The Rangeland Journal 30, 3-14.

Stafford Smith, D.M., Cribb, J., 2009. Dry Times: Blueprint for a Red Land. CSIRO Publishing, Melbourne.

Stafford Smith, D.M., McAllister, R.R.J., 2008. Managing dryland natural resources for spatial and temporal variability - an approach from first principles. The Rangeland Journal 30, 15-27.

Stafford Smith, D.M., Moran, M., Seemann, K., 2008. The community-settlement nexus - drivers of 'viability' in remote areas. The Rangeland Journal 30, $123-135$.

Sternberg, T., 2008. Environmental challenges in Mongolia's dryland pastoral landscape. Journal of Arid Environments 72, 1294-1304

Strehlow, T.G.H., 1970. Geography and the totemic landscape in central Australia: a functional study. In: Berndt, R.M. (Ed.), Australian Aboriginal Anthropology. Australian Institute of Aboriginal Studies/UWA Press, Perth, pp. 92-140.

Taylor, J., Brown, D., Bell, M., 2006. Population Dynamics and Demographic Accounting in Arid and Savanna Australia: Methods, Issues and Outcomes. DKCRC Research Report 16. Desert Knowledge and Tropical Savannas Cooperative Research Centres, Alice Springs.

Taylor, J., Ffowcs-Williams, I., Crowe, M., 2008. Linking desert businesses: the impetus, the practicalities, the emerging pay-offs, and building on the experiences. The Rangeland Journal 30, 187-195.

Toivonen, R., Kovanen, L., Kivela, M., Onnela, J.P., Saramaki, J., Kaski, K., 2009. A comparative study of social network models: network evolution models and nodal attribute models. Social Networks 31, 240-254.

Tonts, M., 2005. Competitive sport and social capital in rural Australia. Journal of Rural Studies 21, 137-149.

Watts, D.J., 2003. Six Degrees: The Science of a Connected Age. William Heinemann, London. 